\title{
cenizas de combustibles españoles propiedades aglomerantes
}

\author{
PABLO GARCIA DE PAREDES Y GAIBROIS \\ Ldo, en Cioncias Quimicas \\ Jefe de la Seceión de Estudies Especlales sobre Aglomeranles
}

El deseo que anima a la Dirección de este Instituto en orden a la máxima utilización de cuantos subproductos ofrezca la industria española y posean propiedades que permitan emplearlos en la construcción. con el consiguiente abaratamiento de la misma, ha sido la idea rectora de este primer o preliminar estudio de las cenizas que algunos combustibles españoles dejan al ser utilizados en las centrales térmicas.

Además de las propiedades que como aglomerante o adición activa a los aglomerantes normalizados posean las cenizas (volantes o de parrilla), el mejor conocimiento de sus caracteres técnicos presenta el interés de poder llegar a identificar su presencia en los aglomerantes cuando su adición se haya realizado fraudulentamente; ya que, si bien este extremo no podrá tener lugar en las fábricas, cabe, en una situación deficitaria, que la realicen manos anónimas de intermediarios.

Esta nota, que sólo amplía algunos extremos de la monografía n. 175 publicada años hace por el Dr. D. Demetrio Gaspar Tebar, fiene un carácter de primera aproximación, pues el limitado número de casos examinados no permite generalizar los resultados sin una más exhaustiva experimentación.

Los productos sólidos que la combustión de los carbones proporciona, pueden ser, como es sabido, denominados «cenizas volantes», si el combustible se quema después de pulverizado, o «de parrilla», en caso de no haber sufrido la molturación citada. Naturalmente, aún tratándose del mismo combustible, el material es diferente, porque ni las temperaturas a que se encontró sometido, ni las condiciones de enfriamiento, ni el ambiente en el cual se realizó la combustión, ‘son similares.

El material designado con el número 145 es una ceniza de parrilla; los demás son cenizas volantes.

\section{Composición química}

La Sociedad Norteamericana de Ensayos (A. S. T. M.), en su especificación C 350 - $54 \mathrm{~T}$, fija los siguientes fímites pora la aceptación de estos materiales como aglomerantes o adición a los mismos:

$\begin{array}{lr}\mathrm{SiO}_{2} & 40,0 \% \text { mínimo } \\ \mathrm{MgO} & 3,0 \% \text { máximo } \\ \mathrm{SO}_{3} & 3,0 \% \text { máximo } \\ \text { Humedad } & 3,0 \% \text { máximo } \\ \text { Pérdida de peso } & \\ \quad \text { al calcinar } & 12,0 \% \text { máximo } \\ \text { Alcalis ( } \mathrm{Na}_{2} \mathrm{O} \text { ) } & 1,5 \% \text { máximo }\end{array}$

El contenido de álcalis sólo se tendrá en cuenta a petición del usuario.

En cuanto a la cantidad de carbón sin quemar, Peters (Betonstein Ztg 1957, H.1, S.27) recomienda mantenerse entre el $3 y$ el $5 \%$.

En el cuadro $n .^{\circ} 1$ se exponen los resultados de los análisis del material estudiado; como puede comprobarse fácilmente, las cantidades preponderantes corresponden a la sílice, la alúmina y el óxido férrico. Existen diferencias notables en la cuantía de la fracción soluble en ácido clorhídrico $y$ carbonato sódico; se ha destacado esta 
porción, puesto que para muchos autores precisamente tienen interés, ya que asimilan el caracter aglomerante de las cenizas solamente a los elementos solubles.

Como no existe un método que permita fijar, de un modo categórico, el valor de las cenizas como aglomerantes hidráulicos, se ha adoptado, en esta nota, con ese carácter la capacidad de fijación de cal por las mismas, siguiéndose un procedimiento, el cual, si bien es harto lento, nos permite investigar algo acerca de los compuestos que se forman en la reacción de fijación del calcio.

Para ello se coloca una cantidad de la ceniza que se examina en contacto con agua de cal saturada, $y$, a intervalos regulares de tiempo, se mide la concentración del calcio (expresada como $\mathrm{CaO}$ ) en la fase liquida del sistema. Para que los datos puedan ser comparables se ha mantenido fija la temperatura, adoptándose la de $37^{\circ} \mathrm{C}$, porque, sin ser tan baja que la reacción transcurriera con extremada lentifud, no influía en el sentido de favorecer la formación de compuestos diferentes a los que se crearan cuando la reacción tiene lugar en el seno de un mortero o de un hormigón en las condiciones más generales de su utilización.

En todas las manipulaciones se evitó la acción del carbónico atmosférico mediante el empleo de una atmósfera de nitrógeno exento de $\mathrm{CO}_{2}$. Al mismo tiempo que se realizan las tomas de líquido y su reposición por nuevas cantidades de agua de cal safurada, se extrajeron algunos miligramos de la fase sólida y se les examinó con el microscopio dispersos en agua de cal. Este examen, al que se acompañó con la obtención de microfotografías, permite en una primera aproximación, conocer qué compuestos son los que tienen nacimiento durante la reacción. Tal conocimiento se puede traducir en la posibilidad de enjuiciar acerca de cuóles son los componentes más estimables en las cenizas en orden a su valoración como aglomerantes.

Decimos que de los preparaciones microscópicas obtenemos, wen primera aproximación", datos sobre los nuevos compuestos, porque sólo mediante el conocimiento de la estructura cristalína de éstos, obtenido con el examen de los espectros de rayos $X_{t}$ se puede alcanzar una mayor certidumbre. En fecha próxima esperamos completar de este modo las observaciones realizadas.

Los resultados logrados mediante el análisis de la fase líquida del sistema cenizas-agua de cal, se exponen en los cuadros n.os 2 al 7; en ellos puede apreciarse la diferente marcha del fenómeno de uno a otras cenizas. En realidad la diferencia es más de índole cuantitativa, ya que las variaciones de la velocidad de reacción siguen una curva similar. A pesar de que la relación sólido-líquido es en este sistema distinta de la que existe en los morteros y hormigones, la circunstancia de que tanto en éstos como en el sistema estudiado la fase líquida sea agua saturada de hidróxido cólcico, permite suponer que en ambos casos las reacciones discurren de forma similär.

La colección de fotos que se inserta, escogidas entre varios centenares de negativos, permiten apreciar la presencia de fres tipos diferentes de formaciones: Agujas que a veces forman «erizos» alrededor de los granos, placas hexagonales $y$ masas amorfas o, mejor, informes. El examen de los compuestos cristalinos con luz polarizada convergente, la evolución de las placas hexagonales a formas octaédricas y la comparación de las fatos obtenidas con las publicados por otros investigadores que operaron con especies puras, nos permite asegurar que las agujas están formadas por el sulfoaluminato engendrado a expensas del sulfato en que se convierte el azufre de las cenizas. Las placas hexagonales son, con bastante seguridad, cristales de aluminato tricálcico en su formo metaestable $y$, quizás, mezclas formadas por aluminatos cálcicos y ferro-aluminatos.

Los silicatos no aparecen visiblemente, quizás porque sus índices de refracción los hagan no visibles, pero es muy posible que constituyan las formaciones amorfas que se han indicado.

El cuadro $n .^{\circ} 8$ contiene la granulometría de las cenizas tal como se recibieron. Los datos se obtuvieron por tamizado hasta las 50 micras, y el material que pasó a través del tamiz de esa luz se sometió a la levigación con aire en el fluorómetro de Pearson, con lo cuol se conoció el valor de las fracciones comprendidas entre 45 y 0 micros. 


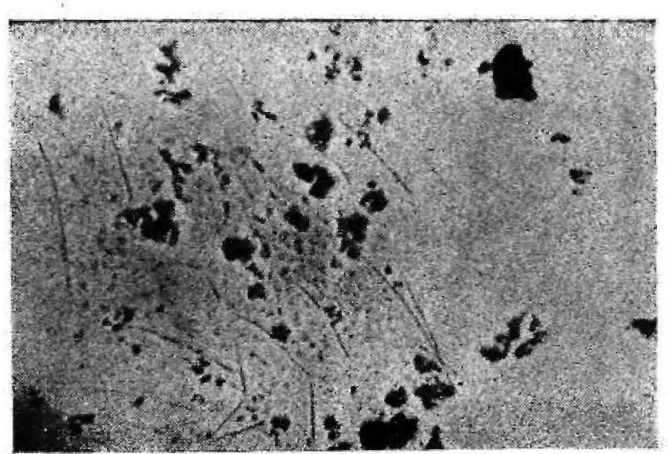

Ceniza 148 + agua de cal 8 dias

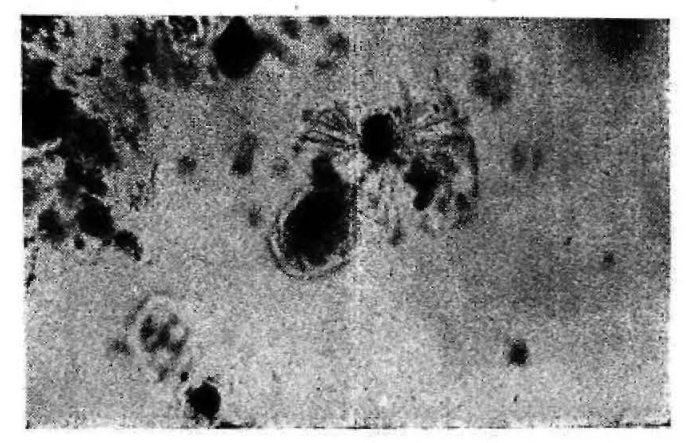

Ceniza 148 + agua de cal 60 días

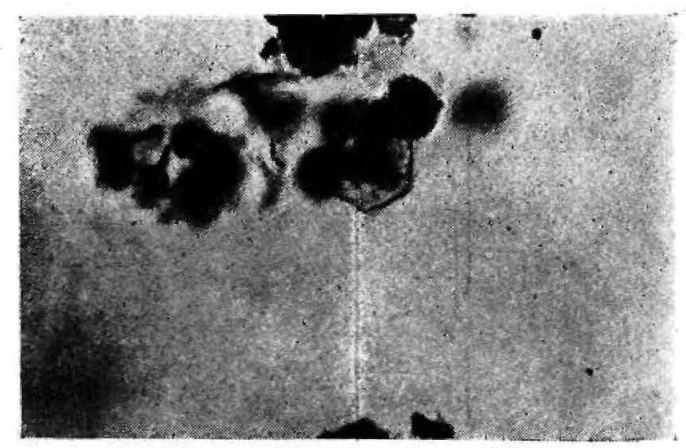

Ceniza 154 + agua de cal 28 dias

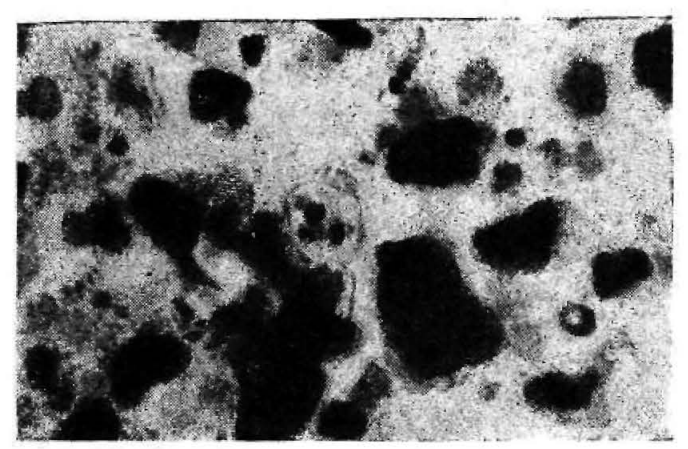

Ceniza 148 + agua de cal 31 días

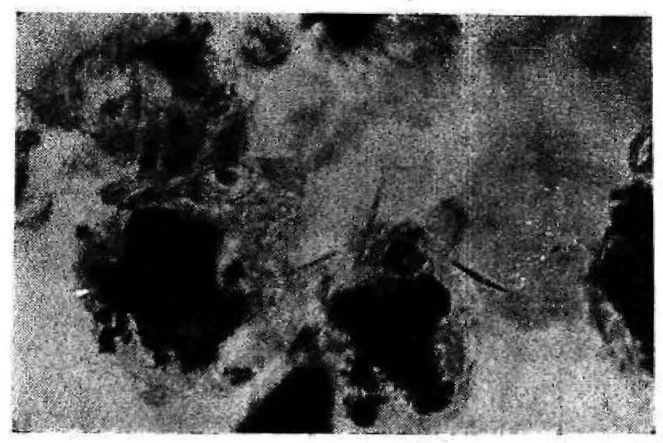

Ceniza 148 + agua de cal 120 dias

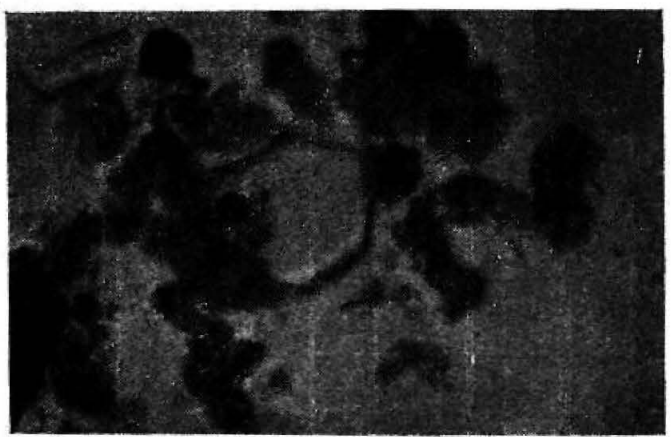

Ceniza 154 + agua de cal 60 dlas 


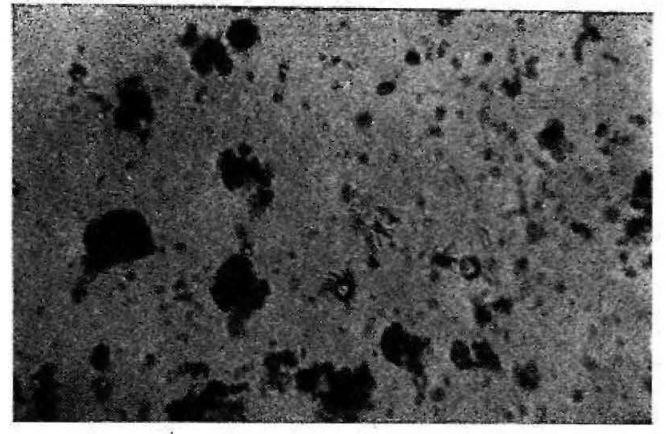

Ceniza $150+$ agua de cal 7 dras

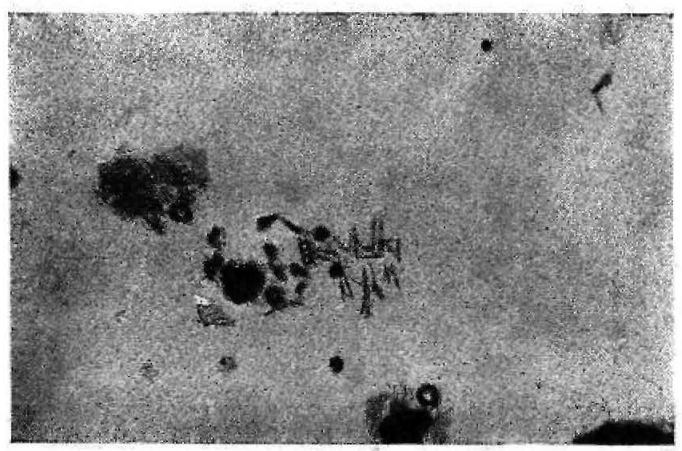

Ceniza 153 + agua de cal 28 dias

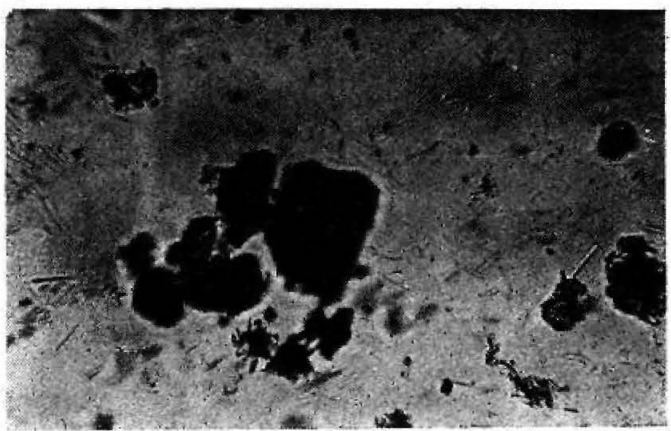

Ceniza $145+$ agua de cal 8 dias

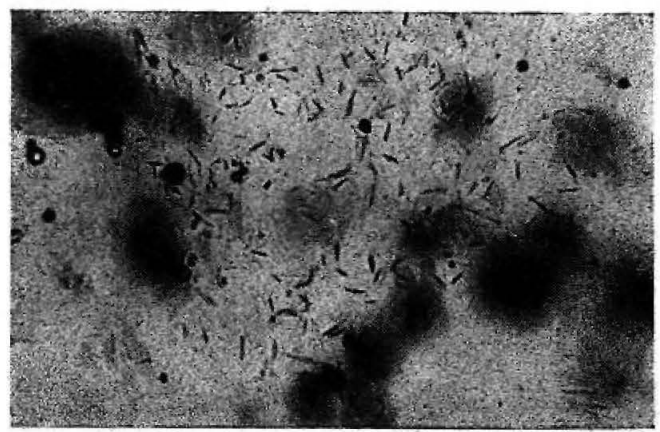

Ceniza 153 + agua de cal 8 días

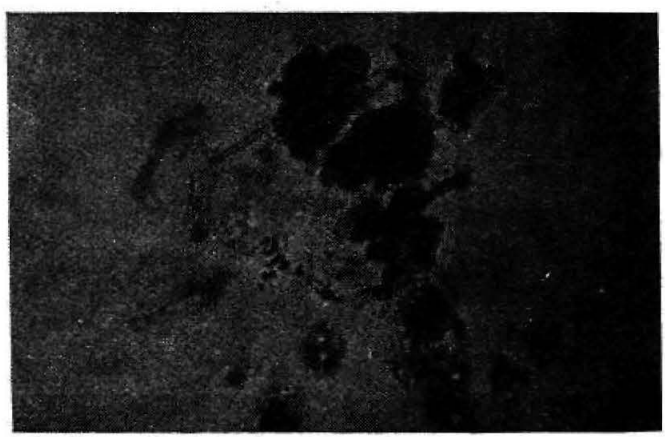

Ceniza 153 + agua de cal 60 días

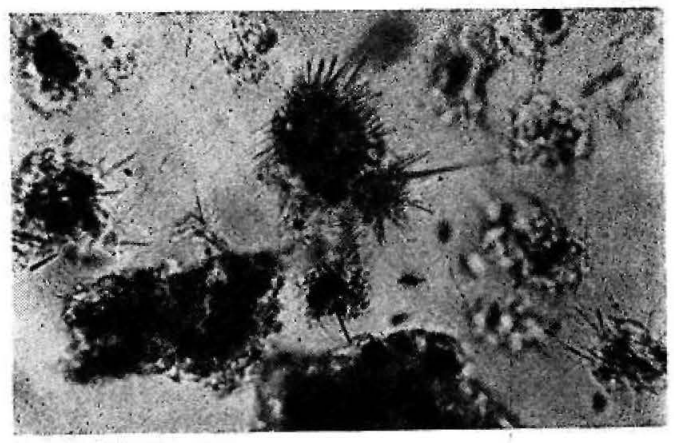

Ceniza 145:+ agua de cal 90 días 


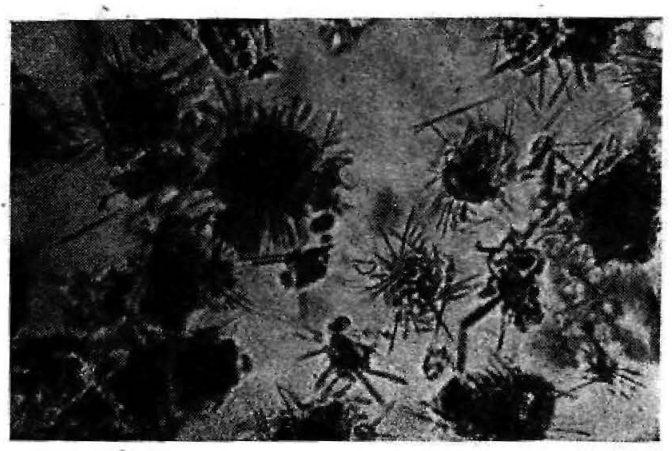

Ceniza 145 + agua de cal 150 dias

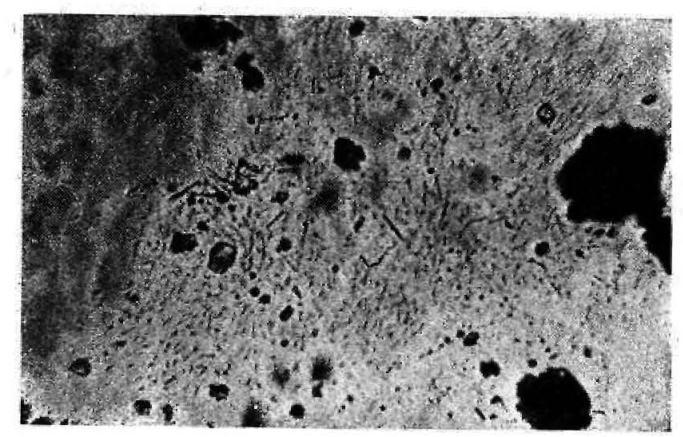

Ceniza $146-1$ + agua de cal 8 días

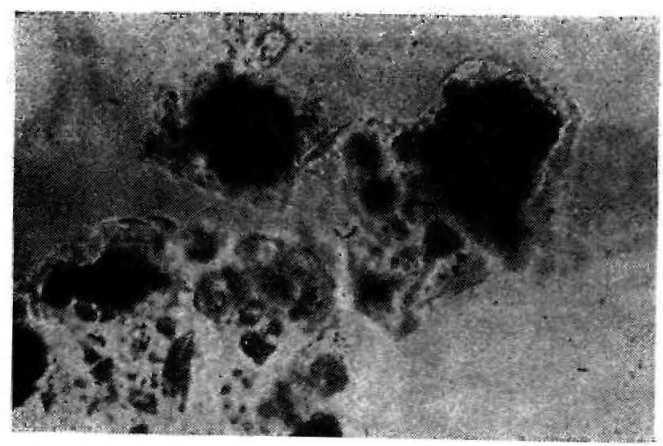

Ceniza 146-1 + agua de cal 150 dias

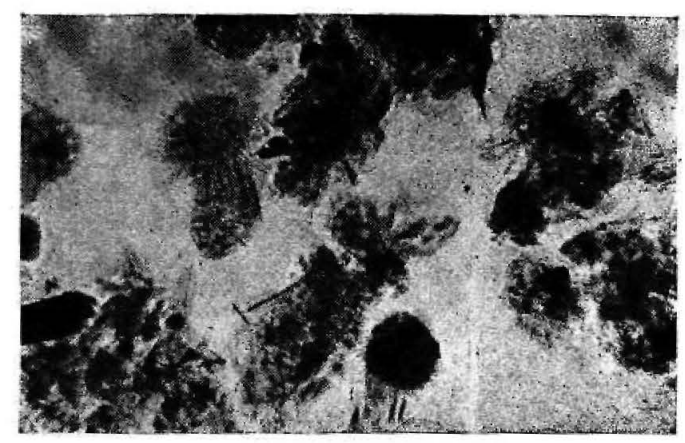

Ceniza 145 + agua de cal 180 días

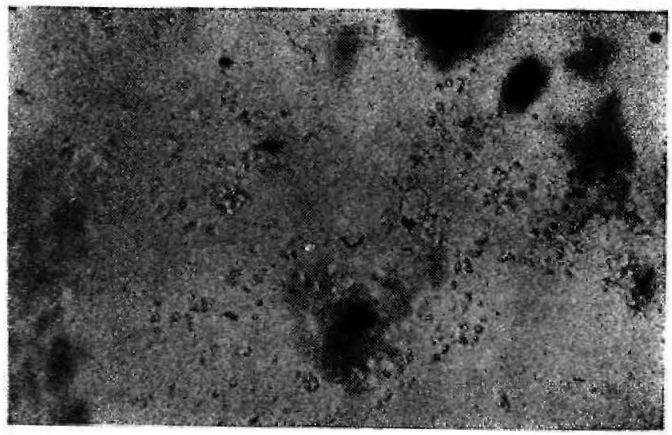

Ceniza $146-1$ + agua de cal 28 dias

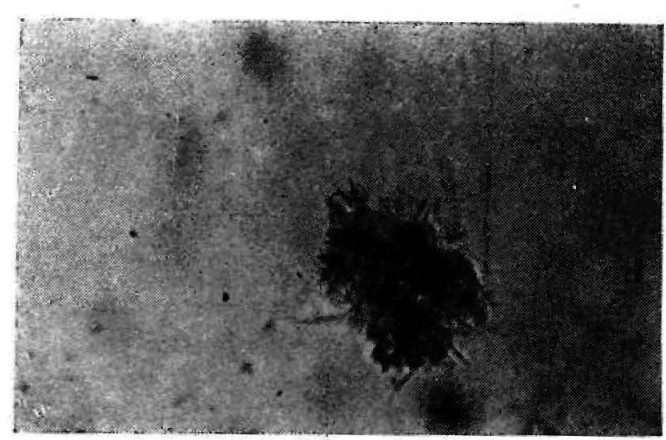

Ceniza 146-1 + agua de cal 90 días 


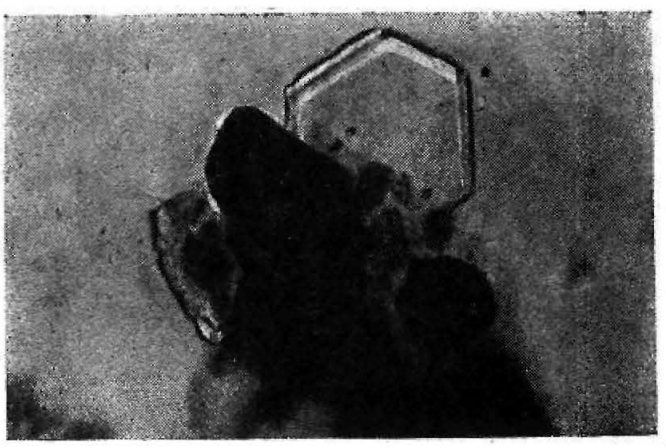

Ceniza 146-II + agua de cal 28 dias

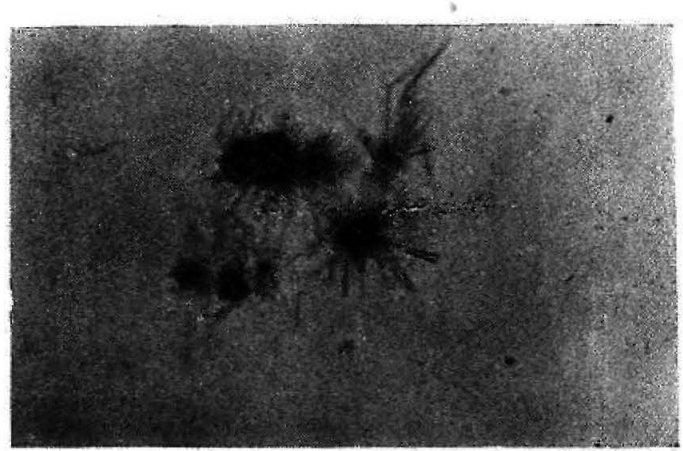

Ceniza 146-1 + agua de eal 240 dias

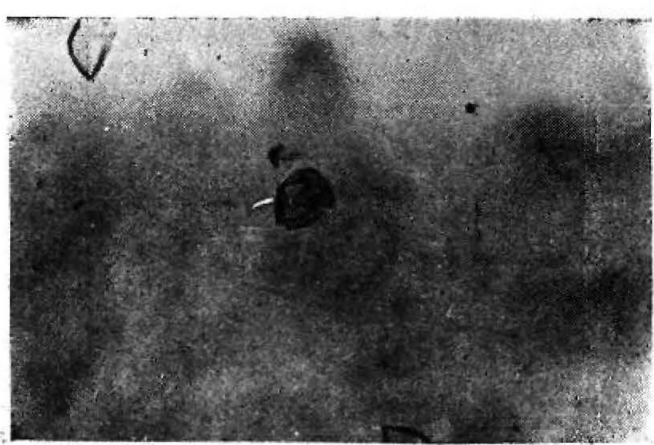

Ceniza $146-11$ + agua de cal 90 días

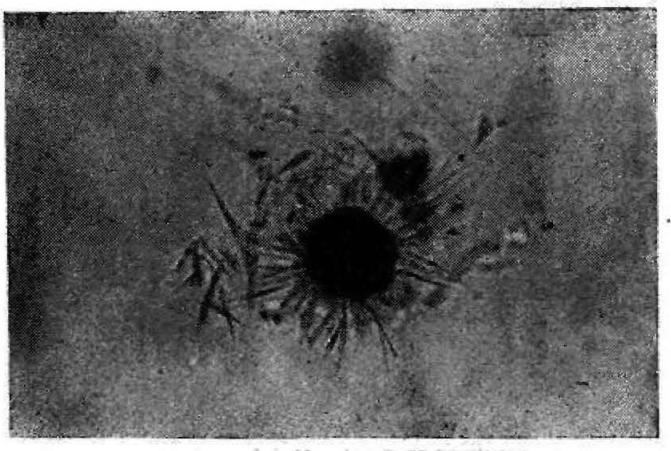

Ceniza 146-1 + agua de cal 180 dias

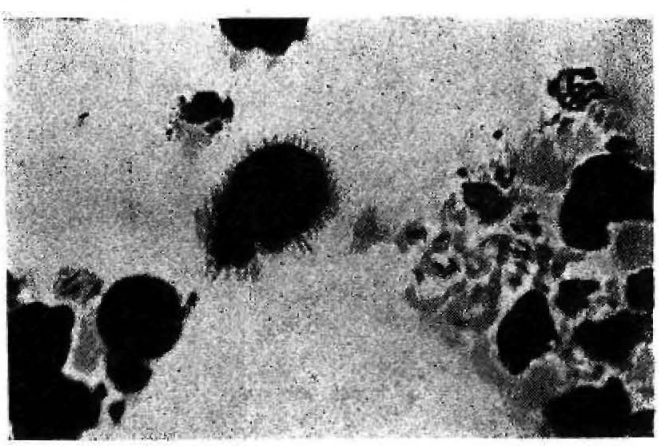

Ceniza $146.11+$ agua de cal 28 dias

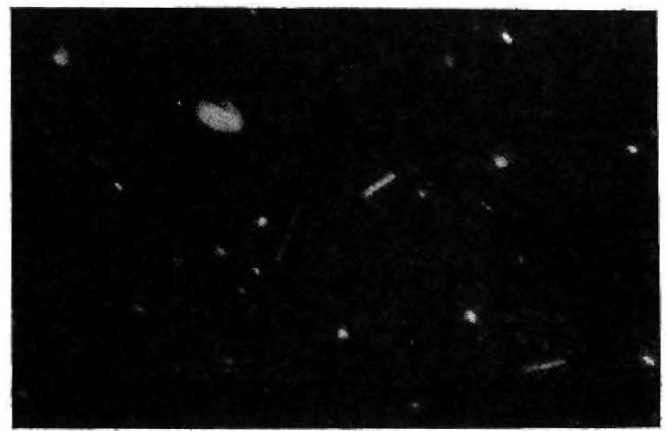

Ceniza 146-II + agua de cal 150 días 


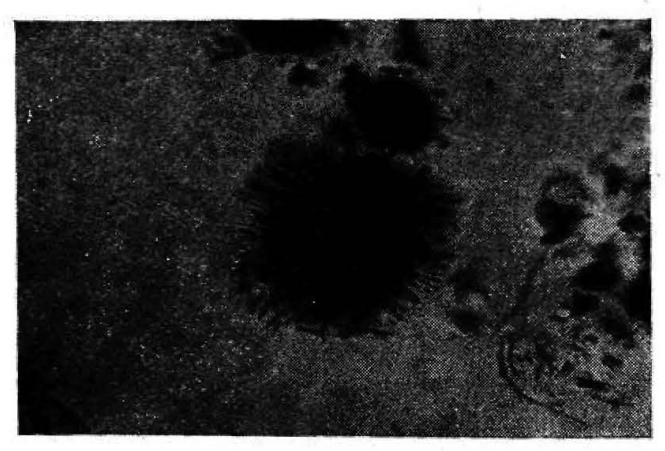

Ceniza $146-11+$ agua de cal 180 dias

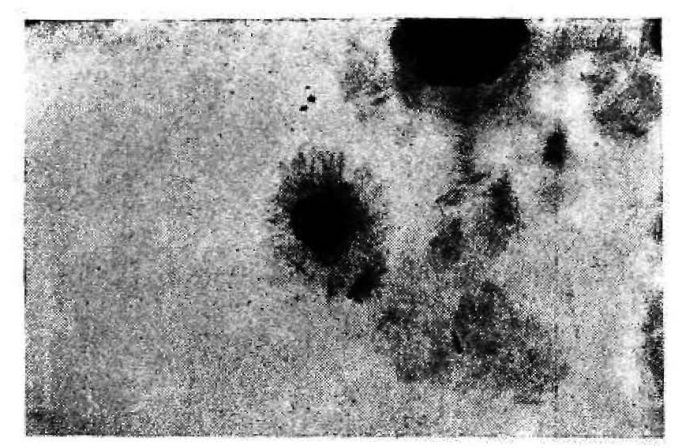

Ceniza 146-11 + agua de cal 210 días

Composición química de las cenizas

\begin{tabular}{lccc}
\multicolumn{1}{c}{ NÚMERO } & 145 & $146-1$ & $146-11$ \\
Carbono $\mathrm{C}$ & 3,70 & 1,00 & 0,00 \\
Azufre $\left(\mathrm{SO}_{2}\right)$ & 0,06 & 0,14 & 0,08 \\
$\mathrm{CO}_{2}$ & 6,40 & &
\end{tabular}

$\begin{array}{lll}150 & 153 & 154 \\ 1,39 & 0,18 & 0,32 \\ & 0,03 & 0,00 \\ 4,20 & 3,50 & 0,00\end{array}$

Soluble en $\mathrm{HCl}$

$\begin{array}{lrllllrl}\mathrm{SiO}_{2} & 5,39 & 5,16 & 3,65 & 1,22 & 7,13 & 10,04 & 1,93 \\ \mathrm{Al}_{2} \mathrm{O}_{3} & 2,24 & 3,94 & 3,72 & 1,21 & 4,84 & 2,08 & 0,15 \\ \mathrm{Fe}_{2} \mathrm{O}_{3} & 4,50 & 5,91 & 3,34 & 0,40 & 4,08 & 4,08 & 1,93 \\ \mathrm{CaO} & 8,08 & 5,07 & 4,81 & 1,10 & 4,58 & 4,90 & \\ \mathrm{MgO} & 0,17 & 0,34 & 0,95 & 0,14 & 0,32 & 0,32 & \\ \mathrm{SO}_{3} & 6,91 & 1,34 & 0,70 & & 0,17 & 0,00 & \end{array}$

Insoluble en $\mathrm{HCl}$

$\mathrm{SiO}_{2}$

$\mathrm{Al}_{2} \mathrm{O}_{3}$

$\mathrm{Fe}_{2} \mathrm{O}_{3}$

$\mathrm{CaO}$

$\mathrm{MgO}$

Alcalis y s.d.

32,68
9,55
17,40
1,54
0,84

33,42

19,09

22,39

2,20

0,84

148

39,89
23,99
17,25
1,32
0,21

63,73

20,75

6,54

0,53

1,17

3,21

36,14
17,00
17,33
0,77
0,00
2,05

32,29

63,91

$22,07 \quad 25,68$

$18,31 \quad 3,52$

$1,33 \quad 1,48$

$0,44 \quad 1,06$

$0,43 \quad 0,02$ 
Cantidades de $\mathrm{CaO}$ (en $\mathrm{mg}$ ) fijadas por las cenizas

GRAVIMETRIAS

\begin{tabular}{|c|c|c|c|c|c|c|c|c|c|}
\hline \multirow{3}{*}{$\begin{array}{l}\text { Número } \\
\text { tiempo } \\
\text { en dies } \\
\text { purcialet lutalor }\end{array}$} & \multicolumn{3}{|c|}{145} & \multicolumn{3}{|c|}{$146-1$} & \multicolumn{3}{|c|}{146.11} \\
\hline & \multicolumn{2}{|c|}{$\mathrm{mg}$ do $\mathrm{CaO}$} & \multirow{2}{*}{$\begin{array}{l}\text { velocidad } \\
\text { de } \\
\text { reacción }\end{array}$} & \multicolumn{2}{|c|}{ mg. de CaO } & \multirow{2}{*}{$\begin{array}{l}\text { velocidad } \\
\text { de } \\
\text { recection }\end{array}$} & \multicolumn{2}{|c|}{$\mathrm{mg} \cdot \mathrm{de} \mathrm{CaO}$} & \multirow{2}{*}{$\begin{array}{l}\text { velocidad } \\
\text { de } \\
\text { reoceión }\end{array}$} \\
\hline & porciales & totales & & porciales & ratales & & parciales & totales & \\
\hline $7-7$ & 47,8 & 47,8 & 6.8 & 15,8 & 15,8 & 2,3 & 4,2 & 4,2 & 0,6 \\
\hline $21-28$ & 73,6 & 121,4 & 2,6 & 62,2 & 78,0 & 2,94 & 73,3 & 77,5 & 2,61 \\
\hline $32 \cdot 60$ & 27,0 & 148,4 & 0,8 & 63,2 & 141,2 & 1,91 & 53,0 & 130,5 & 1,65 \\
\hline $30 \cdot 90$ & 55,1 & 203,5 & 1,8 & 40,3 & 181,5 & 1,34 & 40,2 & 170,7 & 1,34 \\
\hline $30 \cdot 120$ & 30,1 & 233,6 & 1,03 & 34,5 & 216,0 & 1,15 & 38,3 & 209,0 & 1,27 \\
\hline $30-150$ & 38,0 & 271,6 & 1,26 & 31,1 & 247,1 & 1,03 & 40,0 & 249,0 & 1,33 \\
\hline $30-180$ & 34,7 & 306,3 & 1,15 & $5 I, 8$ & 298,9 & 1,72 & 61,6 & 310,6 & 2,05 \\
\hline $30-210$ & 31,5 & 337,8 & 1,05 & 24,9 & 323,8 & 0,83 & 27,3 & 337,9 & 0,90 \\
\hline $30 \cdot 240$ & 18,8 & 346,6 & 0,60 & 24,5 & 348,3 & 0,80 & 30,4 & 368,3 & 1,01 \\
\hline $60-300$ & 26,3 & 372,9 & 0,44 & 28,8 & 377,1 & 0,45 & 29,8 & $398 ; 1$ & 0,50 \\
\hline $60 \cdot 360$ & 16,0 & 388,9 & 0,27 & 17,6 & 394,7 & 0,29 & 21,8 & 419,9 & 0,36 \\
\hline $60 \cdot 420$ & 19,9 & $408 ; 8$ & 0,33 & 18,7 & 413,4 & 0,31 & 17,3 & 437,2 & 0,28 \\
\hline
\end{tabular}

Cantidades de $\mathrm{CaO}$ (en $\mathrm{mg}$ ) fijadas por las cenizas

GRAVIMETRIAS

\begin{tabular}{|c|c|c|c|c|c|c|}
\hline \multirow{3}{*}{$\begin{array}{c}\text { Número } \\
\text { Tlempo } \\
\text { on dios }\end{array}$} & \multicolumn{3}{|c|}{147} & \multicolumn{3}{|c|}{148} \\
\hline & \multicolumn{2}{|c|}{$\mathrm{mg}$ do CaO } & \multirow{2}{*}{$\begin{array}{l}\text { velocidad } \\
\text { de de } \\
\text { reacelón }\end{array}$} & \multicolumn{2}{|c|}{ mg de CaO } & \multirow{2}{*}{$\begin{array}{l}\text { velocidac } \\
\text { de } \\
\text { reaction }\end{array}$} \\
\hline & parciales & Potales & & porcialess & totales & \\
\hline $7 \cdot 7$ & 18,6 & 18,6 & 2,7 & 32 & 32 & 4,57 \\
\hline $21-28$ & 91,1 & 1097,7 & 3,26 & 84,9 & 116,9 & 4,00 \\
\hline $32-60$ & 33,9 & 943,6 & 1,06 & 27.9 & 141,8 & 0,78 \\
\hline $30-90$ & 50,9 & 194,0 & 1,69 & 63,2 & 205,0 & 2,10 \\
\hline $30-120$ & 41,5 & 236,0 & 1,38 & 43,5 & 248,5 & 1,45 \\
\hline $30 \cdot 150$ & 46,0 & 282,0 & 1,53 & 40,0 & 288,5 & 1,33 \\
\hline $30-180$ & 54,0 & 336,0 & 1,80 & 34,0 & 322,5 & 1,13 \\
\hline $30-210$ & 57,0 & 393,0 & 1,90 & 29,8 & 352,3 & 0,99 \\
\hline $30-240$ & 28,3 & 421,3 & 0,94 & 31,3 & 383,6 & 1,04 \\
\hline $60 \cdot 300$ & 41,8 & 463,1 & 0,70 & 38,8 & 422,4 & 0,65 \\
\hline $60-360$ & 33,2 & 496,3 & 0,55 & 27,7 & $450, \mathrm{~T}$ & 0,46 \\
\hline $60-420$ & 16,8 & $5 \mid 3,1$ & 0,28 & 27,8 & 477,9 & 0,46 \\
\hline
\end{tabular}




\section{Cantidades de $\mathrm{CaO}$ (en mg) fijadas por las cenizas}

GRAVIMETRIAS

\begin{tabular}{|c|c|c|c|c|c|c|c|c|c|}
\hline \multirow{3}{*}{$\begin{array}{c}\text { Número } \\
\text { Tiempo } \\
\text { en dlas } \\
\text { parolalas lataias }\end{array}$} & \multicolumn{3}{|c|}{150} & \multicolumn{3}{|c|}{153} & \multicolumn{3}{|c|}{154} \\
\hline & \multicolumn{2}{|c|}{ mg de $\mathrm{CaO}$} & \multirow{2}{*}{$\begin{array}{l}\text { velocidad } \\
\text { de } \\
\text { racción }\end{array}$} & \multicolumn{2}{|c|}{$\mathrm{mg}$ de $\mathrm{CoO}$} & \multirow{2}{*}{$\begin{array}{c}\text { velocidad } \\
\text { de } \\
\text { recceción }\end{array}$} & \multicolumn{2}{|c|}{$\mathrm{mg}$ de $\mathrm{CaO}$} & \multirow{2}{*}{$\begin{array}{l}\text { velocidad } \\
\text { de } \\
\text { reotcton }\end{array}$} \\
\hline & parciales & rotoles & & parsiclet & totales & & parcioles & totales & \\
\hline $7-7$ & 36,2 & 36,2 & 5,17 & 6,0 & 6,0 & 0,85 & 6,4 & 6,4 & 0,91 \\
\hline $21-28$ & 86,3 & 122,5 & 4,10 & 27,5 & 33,5 & 1,30 & 81,2 & 87,6 & 3,86 \\
\hline $32-60$ & 54,5 & 177,0 & 1,70 & 54,5 & 88,0 & 1,70 & 56,4 & 144,0 & 1,75 \\
\hline $30-90$ & 44,6 & 221,6 & 1,48 & 47,1 & 135,1 & 1,57 & 42,4 & 186,2 & $1,4\rceil$ \\
\hline $30-120$ & 44,9 & 266,5 & 1,50 & 38,8 & 173,9 & 1,27 & 37,3 & 223,5 & 1,24 \\
\hline $30-150$ & 40,1 & 306,6 & 1,33 & 32,0 & 205,9 & 1,06 & 33,9 & 257,4 & 1,13 \\
\hline $30-180$ & & & & 25,2 & 231,1 & 0,84 & 20,7 & 278,1 & 0,69 \\
\hline $30-210$ & 43,4 & 350,0 & 0,72 & 44,5 & 275,6 & 1,45 & 33,9 & 312,0 & 1,13 \\
\hline $30-240$ & & & & 19,0 & 294,6 & 0,63 & 24,8 & 336,8 & 0,82 \\
\hline $30-270$ & 32,7 & 382,7 & 0,49 & & & & & & - \\
\hline $30-300$ & & & & 25,5 & 320,1 & 0,42 & 31,8 & 368,6 & 0,53 \\
\hline
\end{tabular}

Cantidades de $\mathrm{CaO}$ (en mg) fijadas por las cenizas

VOLUMETRIAS

\begin{tabular}{|c|c|c|c|c|c|c|c|c|c|}
\hline \multirow{3}{*}{$\begin{array}{l}\text { Número } \\
\text { Tiempo } \\
\text { en dias }\end{array}$} & \multicolumn{3}{|c|}{145} & \multicolumn{3}{|c|}{146.1} & \multicolumn{3}{|c|}{146.11} \\
\hline & \multicolumn{2}{|c|}{$\mathrm{mg}$ de $\mathrm{CoO}$} & \multirow{2}{*}{$\begin{array}{l}\text { velocidad } \\
\text { de } \\
\text { reacción }\end{array}$} & \multicolumn{2}{|c|}{$\mathrm{mg}$ de $\mathrm{CaO}$} & \multirow{2}{*}{$\begin{array}{c}\text { velocidad } \\
\text { de } \\
\text { reacción }\end{array}$} & \multicolumn{2}{|c|}{$\mathrm{mg}$ de $\mathrm{CoO}$} & \multirow{2}{*}{$\begin{array}{l}\text { velocidac } \\
\text { de } \\
\text { reacrión }\end{array}$} \\
\hline & parciales & totales & & parciales & totales & & parciales & totales & \\
\hline $7-$ & 66,9 & 66,9 & 9,6 & 23,8 & 23,8 & 3,4 & 9,24 & 9,24 & 1,32 \\
\hline $21-28$ & 58,7 & 125,6 & 2,9 & 48,93 & 72,73 & 2,33 & 54,60 & 63,84 & 2,60 \\
\hline $32-60$ & $28, i$ & 153,7 & 0,88 & 60,80 & 133,53 & 1,90 & 45,76 & 109,60 & 1,43 \\
\hline $30-90$ & 39,0 & 192,7 & 1,3 & 25,80 & 159,33 & 0,86 & 42,00 & 151,60 & 1,40 \\
\hline $30-120$ & 31,14 & 223,84 & 0,9 & 47,70 & 207,03 & 1,59 & 30,00 & 181,60 & 1,00 \\
\hline $30 \cdot 150$ & 36,30 & 260,14 & 1,21 & 90,60 & 297,63 & 3,02 & 44,10 & 225,70 & 1,47 \\
\hline $30-180$ & 31,20 & 291,34 & 1,04 & 34,50 & 332,13 & 1,15 & 39,30 & 265,00 & 1,31 \\
\hline $30-210$ & 20,36 & 311,80 & 0,68 & 28,00 & 360,13 & 0,93 & 28,3 & 293,30 & 0,94 \\
\hline $30-240$ & 18,74 & 330,54 & 0,60 & 18,10 & 378,23 & 0,60 & 27,3 & 320,60 & 0,91 \\
\hline $60-300$ & 13,79 & 344,33 & 0,23 & 21,30 & 399,53 & 0,36 & 25,4 & 346,00 & 0,42 \\
\hline $60-360$ & 19,08 & 363,41 & 0,32 & 20,49 & 420,02 & 0,34 & 21,6 & 367,61 & 0,36 \\
\hline $60-420$ & 14,87 & 378,28 & 0,24 & 11,79 & 431,81 & 0,20 & 17,64 & 385,25 & 0,29 \\
\hline
\end{tabular}


Cuadro N. 6

Cantidades de $\mathrm{CaO}$ (en mg) fijadas por las cenizas

VOLUMETRIAS

\begin{tabular}{|c|c|c|c|c|c|c|}
\hline \multirow{3}{*}{$\begin{array}{l}\text { Número } \\
\text { Tiempo } \\
\text { on díos }\end{array}$} & \multicolumn{3}{|c|}{147} & \multicolumn{3}{|c|}{148} \\
\hline & \multicolumn{2}{|c|}{$\mathrm{mg}$ de CaO } & \multirow{2}{*}{$\begin{array}{l}\text { velocidad } \\
\text { de } \\
\text { reaccion }\end{array}$} & \multicolumn{2}{|c|}{$\mathrm{mg} d \theta \mathrm{CaO}$} & \multirow{2}{*}{$\begin{array}{l}\text { valocidad } \\
\text { de } \\
\text { reacción }\end{array}$} \\
\hline & parciales & totales & & parcialess & totates & \\
\hline $7-7$ & 21,4 & 21,4 & 3,06 & 29,6 & 29,6 & 4,24 \\
\hline $21-28$ & 75,0 & 96,4 & 3,60 & 68,0 & 97,6 & 3,24 \\
\hline $32-60$ & 30,6 & 127,0 & 0,96 & 28,7 & 126,3 & 0,90 \\
\hline $30-90$ & 51,50 & 178,5 & 1,65 & 51,6 & 177,9 & 1,72 \\
\hline $30 \cdot 120$ & 32,40 & 210,9 & 1,08 & 34,8 & 2127 & 1,16 \\
\hline $30 \cdot 150$ & 42,00 & 252,9 & 1,40 & 40,5 & 253,2 & 1,35 \\
\hline $30-180$ & 31,50 & 284,4 & 1,05 & 28,5 & 281,7 & 0,95 \\
\hline $30-210$ & 39,60 & 324,0 & 1,32 & 37,5 & 319,2 & 1,25 \\
\hline $30-240$ & 27,70 & 351,7 & 0,96 & 28,14 & 347,34 & 0,94 \\
\hline $60 \cdot 300$ & 35,80 & 387,5 & 0,60 & 37,57 & 384,91 & 0,63 \\
\hline $60-360$ & 32,30 & 419,8 & 0,53 & 30,55 & 415,46 & 0,51 \\
\hline $60-420$ & 23,29 & 443,0 & 0,38 & $25,3 B$ & 440,84 & 0,42 \\
\hline
\end{tabular}

Cantidades de $\mathrm{CaO}$ (en $\mathrm{mg}$ ) fijadas por las cenizas

VOLUMETRIAS

\begin{tabular}{|c|c|c|c|c|c|c|c|c|c|}
\hline \multirow{3}{*}{$\begin{array}{c}\text { Número } \\
\text { Tiempo } \\
\text { en dilas } \\
\text { parciales futales }\end{array}$} & \multicolumn{3}{|c|}{150} & \multicolumn{3}{|c|}{153} & \multicolumn{3}{|c|}{154} \\
\hline & \multicolumn{2}{|c|}{$\mathrm{mg}$ de $\mathrm{CaO}$} & \multirow{2}{*}{$\begin{array}{l}\text { veloçldad } \\
\text { de } \\
\text { reacción }\end{array}$} & \multicolumn{2}{|c|}{$\mathrm{mg}$ de $\mathrm{CaO}$} & \multirow{2}{*}{$\begin{array}{l}\text { velocidad } \\
\text { de } \\
\text { reaccion }\end{array}$} & \multicolumn{2}{|c|}{$\mathrm{mg}$ de $\mathrm{CaO}$} & \multirow{2}{*}{$\begin{array}{l}\text { velocidad } \\
\text { de } \\
\text { reaction }\end{array}$} \\
\hline & parclates & totales & & parciales & totales & & parciales & totales & \\
\hline $7 \cdot 7$ & 32,72 & 32,72 & 4,67 . & 2,2 & 2,2 & 0,31 & 8,0 & 8,0 & 1,14 \\
\hline $21-28$ & 74,60 & 107,32 & 3,55 & 35,8 & 38,0 & 1,70 & 42,2 & 50,2 & 2,00 \\
\hline $32-60$ & 50,00 & 157,32 & 1,57 & 61,5 & 99,5 & 1,92 & 42,5 & 92,7 & 1,33 \\
\hline $30-90$. & 41,10 & 198,42 & 1,37 & 33,7 & 133,2 & 1,12 & 37,0 & 129,7 & 1,23 \\
\hline $30-120$ & 43,70 & 242,12 & 1,45 & 35,3 & 168,5 & 1,17 & 31,5 & 161,2 & 1,05 \\
\hline $30-150$ & 29,20 & 271,32 & 0,97 & 35,0 & 203,5 & 1,16 & 32,33 & 193,5 & 1,07 \\
\hline $60=180$ & & & & 21,6 & 225,1 & 0,72 & 21,6 & 215,1 & 0,72 \\
\hline $30 \cdot 210$ & 44,96 & 316,28 & 0,75 & 34,2 & 259,3 & 1,14 & 31,2 & 246,3 & 1,04 \\
\hline $30-240$ & & & & 24,4 & 2837 & 0,81 & 28,3 & 274,6 & 0,94 \\
\hline $30-270$ & 33,88 & 350,16 & 0,51 & & & & & & \\
\hline $30-300$ & & & & 25,0 & 308,7 & 0,41 . & 32,2 & 306,8 & 0,53 \\
\hline
\end{tabular}


Cenizas volantes

GRANULOMETRIAS

$\begin{array}{lccccccc}\begin{array}{c}\text { Número } \\ \text { Tamaños de granos } \\ \text { en micras }\end{array} & 145 & 146-1 & 146-11 & 146-111 & 150 & 153 & 154 \\ 1200 & \% & \% & \% & \% & \% & \% & \% \\ 400 & 0,0 & 1,8 & 0,3 & 1,2 & 0,4 & 0,0 & 0,0 \\ 200 & 0,1 & 5,6 & 0,1 & 5,3 & 0,3 & 0,0 & 0,1 \\ 100 & 0,3 & 15,8 & 1,6 & 25,8 & 0,3 & 0,0 & 0,3 \\ 88 & 3,0 & 29,9 & 16,3 & 45,1 & 1,1 & 0,0 & 3,0 \\ 75 & 10,6 & 25,3 & 30,3 & 17,1 & 5,6 & 22,5 & 10,6 \\ 50 & 2,4 & 0,0 & 18,7 & 1,8 & 29,9 & 6,6 & 2,4 \\ \begin{array}{c}\text { Menor de } 50 \\ 45 \text { a } 30\end{array} & 1,67 & 19,0 & 30,8 & 1,9 & 58,9 & 70,0 & 1,6 \\ 30 \text { a } 15 & 36,78 & & & & & 25,4 & 36,78 \\ 15 \text { a } 0 & 45,14 & & & & & 43,4 & 45,14\end{array}$

Preparación y ensayo de aglomerantes portland-ceniza

Se prepararon mezclas de cemento portland y cenizas volantes mezclando los componentes a mano y refinando algo la mezcla en el molino "Vibraton», con el doble objeto de homogeneizar la mezcla, y en algunos casos, ganar finura. No se adicionó cantidad alguna suplementaria de yeso, salvo las numeradas $Z_{17}$ a $Z_{24}$ destinadas a ensayar la influencia del mismo.

La composición de estas mezclas se detalla en el cuadro n. ${ }^{\circ}$; y la correspondiente a las otras mezclas, en el n. ${ }^{\circ} 10$.

Los cuadros 11,12 y 13 contienen los datos de la composición del mortero ensayado, la granulometría del aglomerante y los valores de las resistencias mecánicas del mortero, respectivamente. 
Aglomerantes con cenizas volantes.

$$
\text { COMPOSICION DE LAS MEZCLAS }
$$

\begin{tabular}{|c|c|c|c|c|}
\hline Número & Cenizas N. & Cemento N. & Ceniza $\%$ & Cemento $\%$ \\
\hline 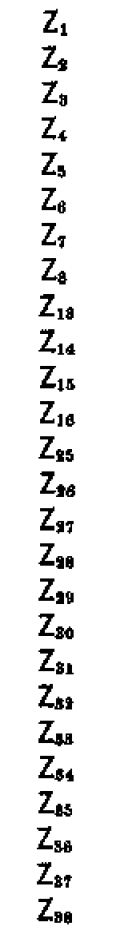 & $\begin{array}{l}145 \\
\text { Id. } \\
\text { id. } \\
\text { id. } \\
148 \\
\text { id. } \\
\text { id. } \\
\text { id. } \\
150 \\
\text { id. } \\
\text { id. } \\
\text { id. } \\
\text { 153 } \\
\text { id. } \\
\text { id. } \\
\text { Id. } \\
\text { id. } \\
\text { Id. } \\
\text { id. } \\
\text { 154 } \\
\text { id. } \\
\text { id. } \\
\text { id. } \\
\text { id. } \\
\text { id. } \\
\text { id. }\end{array}$ & $\begin{array}{l}144 \\
\text { id. } \\
\text { id. } \\
\text { id. } \\
142 \\
\text { id. } \\
\text { id. } \\
\text { id. } \\
\text { id. } \\
\text { id. } \\
\text { id. } \\
\text { id. } \\
\text { id. } \\
\text { id. } \\
\text { id. } \\
\text { id. } \\
\text { id. } \\
\text { id. } \\
\text { id. } \\
\text { id. } \\
\text { id. } \\
\text { id. } \\
\text { id. } \\
\text { id. } \\
\text { id. } \\
\text { id. }\end{array}$ & $\begin{array}{l}10 \\
20 \\
40 \\
80 \\
10 \\
20 \\
40 \\
80 \\
10 \\
20 \\
40 \\
80 \\
10 \\
20 \\
30 \\
50 \\
70 \\
80 \\
90 \\
10 \\
20 \\
30 \\
50 \\
70 \\
80 \\
90\end{array}$ & $\begin{array}{l}90 \\
80 \\
60 \\
20 \\
90 \\
60 \\
60 \\
20 \\
90 \\
80 \\
60 \\
20 \\
90 \\
80 \\
70 \\
50 \\
30 \\
20 \\
10 \\
90 \\
80 \\
70 \\
50 \\
30 \\
20 \\
10\end{array}$ \\
\hline
\end{tabular}

Cuadro N. to

Composición de las mezclas destinadas al estudio de la influencia del yeso en las propiedades técnicas

CEMENTO 142 CENIZA VOLANTE 148

$Z_{17}$ (80\% de cenizas) y $2 \%$ de yeso refinado en el molino

$Z_{19}\{80 \%$ de cenizas $)$ y $3 \%$ de yeso id. id.

$Z_{18}$ (80\% de cenizas) y $2 \%$ de yeso sin refinar

$Z_{* 0}$ (80\% $\%$ de cenizas) y $3 \%$ de yeso id. id.

$Z_{91}$ (20\% de cenizas) y $2 \%$ de yeso refinado en el molino

$Z_{z 2}$ (20\% de cenizas) y $3 \%$ de yeso id. id.

$Z_{21}(20 \%$ de cenizas) y $2 \%$ de yeso sin refinar

$Z_{94}(20 \%$ de cenizas) y $3 \%$ de yeso id. id. 


\section{AGLOMERANTES: PORTLAND - CENIZAS DE CENTRAL TERMICA}

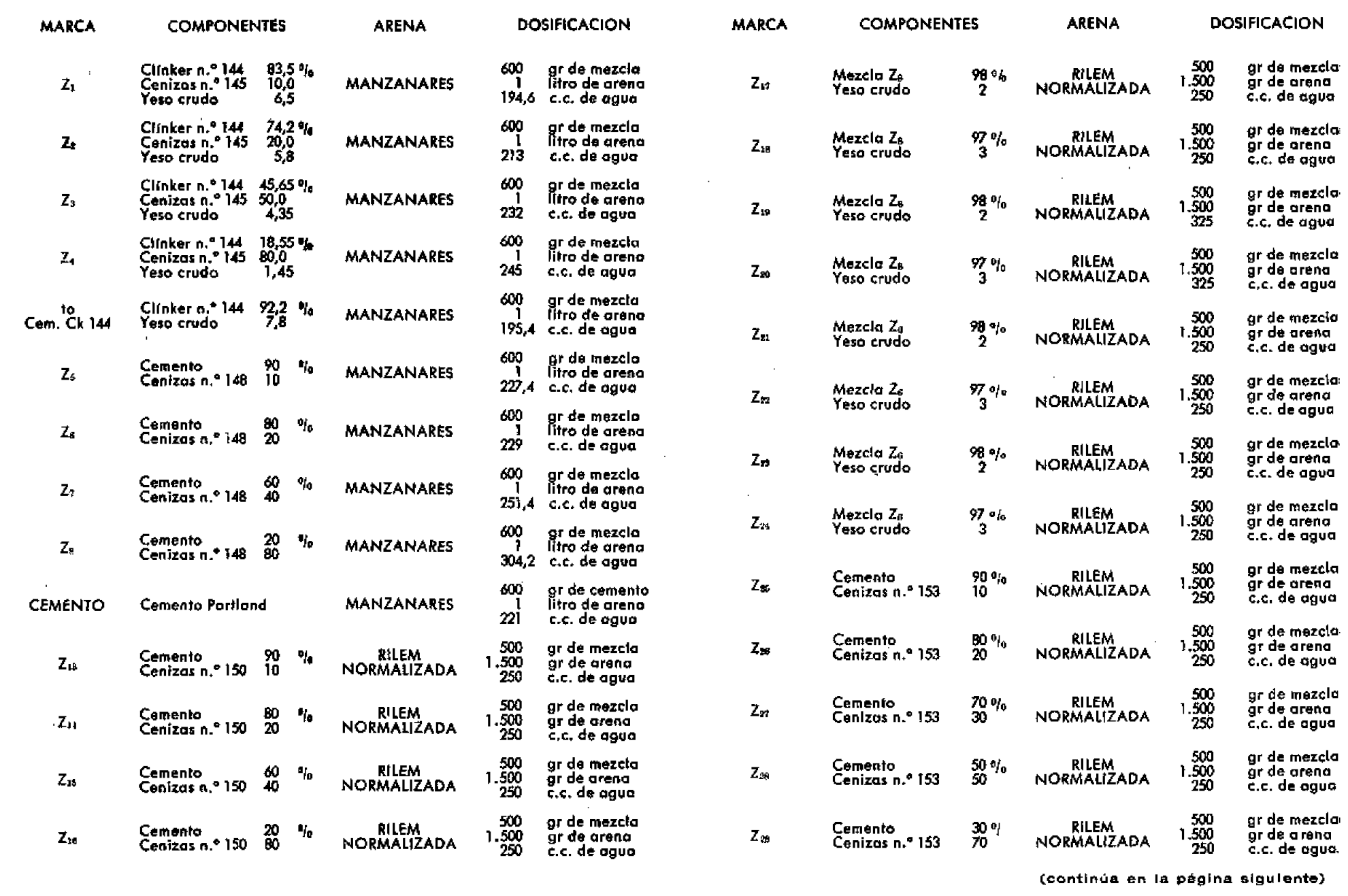


(continuaclón)

\begin{tabular}{|c|c|c|c|c|c|c|c|c|c|c|c|}
\hline MARCA & COMPONEN & & ARENA & & SIFICACION & MARCA & COMPONER & & ARENA & & IFICACION \\
\hline $\mathrm{Z}_{\text {s }}$ & $\begin{array}{l}\text { Cemento } \\
\text { Centzas n. }\end{array}$ & $90 \%$ & $\begin{array}{l}\text { RILEMA } \\
\text { NORMALIZADA }\end{array}$ & $\begin{array}{r}500 \\
1.500 \\
250\end{array}$ & $\begin{array}{l}\text { gr de mezcla } \\
\text { gr de arena } \\
\text { c,c, de oguo }\end{array}$ & $\mathrm{z}_{\mathrm{w}}$ & $\begin{array}{l}\text { Cenento } \\
\text { Cenizes n. } 154\end{array}$ & ${ }_{50}^{50 \%}$ & $\begin{array}{l}\text { RILEM } \\
\text { NORMALILADA }\end{array}$ & $\begin{array}{r}500 \\
1.500 \\
250\end{array}$ & $\begin{array}{l}\text { gr de mezclo } \\
\text { gr de oreria } \\
\text { c.c. de aguo }\end{array}$ \\
\hline$z_{3 *}$ & $\begin{array}{l}\text { Cemento } \\
\text { Cenizas n." } 154\end{array}$ & ${ }_{10}^{90 \%}$ & $\begin{array}{l}\text { RILEM } \\
\text { NORMALIZADA }\end{array}$ & $\begin{array}{r}500 \\
1.500 \\
250\end{array}$ & $\begin{array}{l}\text { gr de mezcla } \\
\text { gr de arena } \\
\text { c.c. de agua }\end{array}$ & $z_{6}$ & $\begin{array}{l}\text { Cemento } \\
\text { Cenizos na. } 154\end{array}$ & $30 \%$ & NORMALLIZADA & $\begin{array}{r}500 \\
1.500 \\
250\end{array}$ & $\begin{array}{l}\text { gr de mazclo } \\
\text { grde orena } \\
\text { c.c. da agua }\end{array}$ \\
\hline$Z_{x y}$ & $\begin{array}{l}\text { Cemento } \\
\text { Centzas nit. }\end{array}$ & ${ }_{20}^{80} \%$ & $\begin{array}{l}\text { RILEM } \\
\text { NORMALIZADA }\end{array}$ & $\begin{array}{l}500 \\
1.500 \\
250\end{array}$ & $\begin{array}{l}\text { gr de mezcla } \\
\text { gr de arena } \\
\text { c.c. de aguou }\end{array}$ & $Z_{S T}$ & $\begin{array}{l}\text { Cemento } \\
\text { Cenizos n." } 254\end{array}$ & $\frac{20 \%}{80}$ & $\begin{array}{l}\text { RILEM } \\
\text { NORMALIZADA }\end{array}$ & $\begin{array}{l}5.500 \\
1.500 \\
250\end{array}$ & $\begin{array}{l}\text { gr de mezelc } \\
\text { gr de arena } \\
\text { c.c. de aguo }\end{array}$ \\
\hline$z_{1}$ & $\begin{array}{l}\text { Cemento } \\
\text { Cenizas n.: } 154\end{array}$ & $3_{30}^{70 \%}$ & $\begin{array}{l}\text { RILEM } \\
\text { NORMALIZADA }\end{array}$ & $\begin{array}{r}500 \\
1.500 \\
250\end{array}$ & $\begin{array}{l}\text { gr de mezcla } \\
\text { gr da arena } \\
\text { c.c. de aguóa }\end{array}$ & $z_{\text {s }}$ & Cemento & $10 \%$ & $\begin{array}{l}\text { RELEM } \\
\text { NORMALIZADA }\end{array}$ & $\begin{array}{l}5.500 \\
1.500 \\
250\end{array}$ & $\begin{array}{l}\text { gr de mercelo } \\
\text { gr de orena } \\
\text { c.c. de aguag }\end{array}$ \\
\hline
\end{tabular}

AGLOMERANTES: PORTLAND - CENIZAS DE CENTRAL TERMICA

FLUOROMETRIA TAMIZADO FLUOROMETRIA

MARCA $<\% 15<\% 30<\% 45>\% 45$ Tamiz Tamiz

$\begin{array}{llllllll}Z_{3} & 60 & 22 & 14 & 4 & 1,1 & \% & 6,55 \%\end{array}$

$\begin{array}{lllllll}\mathrm{Z}_{2} & 64 & 20 & 10 & 6 & 1,1 \% & 7,9 \%\end{array}$

$\begin{array}{lllllll}Z_{2} & 35,8 & 17,9 & 3,2 & 24,4 & 0,6 \% & 18,6 \%\end{array}$

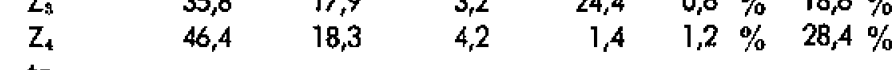

Cem. Ck $144 \quad 32,4 \quad 18,3 \quad 14 \quad 5,6 \quad 1,2 \% \quad 28,4 \%$

$\begin{array}{llllllll}Z_{5} & 43,7 & 19,7 & 10,6 & 1,5 & 1,8 & \% & 22,1 \% \\ Z_{5} & 38,2 & 24,4 & 12,2 & 1,5 & 0,8 & \% & 22,7\end{array}$

$\begin{array}{rrrrrrr}Z_{0} & 38,2 & 24,4 & 12,2 & 1,5 & 0,8 \% & 22,7 \% \\ Z_{i} & 60,3 & 13,9 & 1,5 & 1,5 & 1,2 \% & 21,4 \%\end{array}$

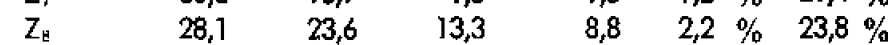

$\begin{array}{lllllll}\text { CEMENTO } & 45,2 & 30,7 & 4,0 & 0,8 & 2,4 \% & 16,8 \%\end{array}$

$\begin{array}{lllllll}Z_{13} & 46,6 & 27,6 & 9,5 & 2,6 & 0,45 \% & 13,3 \%\end{array}$

$\begin{array}{lllllll}\mathrm{Z}_{14} & 44,9 & 39,6 & 1,7 & 0,0 & 1,5 \% & 12,3 \%\end{array}$

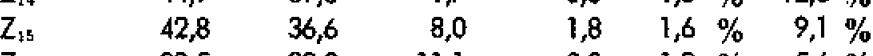

$\begin{array}{lllllll}Z_{1 E} \cdot & 33,5 & 29,8 & 11,1 & 0,0 & 1,2 \% & 5,6 \%\end{array}$

$\begin{array}{lllllll}Z_{17} & 32,1 & 37,8 & 20,8 & 3,8 & 0,1 \% & 5,4 \%\end{array}$

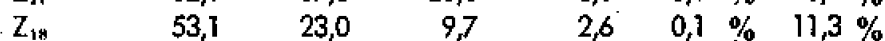

$\begin{array}{llllllll}Z_{16} & 33,8 & 33,8 & 7,7 & 1,5 & 2,1 & \% & 21,0 \%\end{array}$

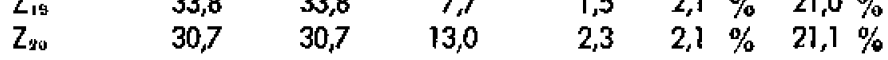

Cuadro N.: 12

MARCA $<\% 15<\% 30<\% 45>\% 45$ Tamiz Tamiz

\begin{tabular}{|c|c|c|c|c|c|c|}
\hline$Z_{21}$ & 56 & 41 & 2 & 1 & & \\
\hline$Z_{23}$ & 69,0 & 25,6 & 3,4 & 0,0 & $0,1 \%$ & $1,3 \%$ \\
\hline$Z_{23}$ & 39,9 & 33,3 & 8,3 & 1,6 & $1,3 \%$ & $15,4 \%$ \\
\hline$Z_{\$_{4}}$ & 46,0 & 29,6 & 4,9 & 1,6 & $1,3 \%$ & $16,5 \%$ \\
\hline$Z_{25}$ & 52,8 & 23,3 & 6,0 & 0,0 & $1,9 \%$ & $15,6 \%$ \\
\hline$Z_{9 B}$ & 52,1 & 13,0 & 13,0 & 1,6 & $1,9 \%$ & $16,6 \%$ \\
\hline$Z_{27}$ & 25,8 & 17,7 & 14,5 & 6,4 & $1,7 \%$ & $17,7 \%$ \\
\hline$Z_{98}$ & 37,2 & 29,1 & 12,9 & 1,6 & $2,0 \%$ & $17,0 \%$ \\
\hline$Z_{89}$ & 33,7 & 32,1 & 12,8 & 1,6 & $2,2 \%$ & $17,5 \%$ \\
\hline$Z_{90}$ & 38,7 & 25,8 & 12,9 & 3,2 & $2,2 \%$ & $17,0 \%$ \\
\hline$Z_{48}$ & 39,4 & 22,9 & 16,4 & 3,3 & $2,2 \%$ & $15,7 \%$ \\
\hline$Z_{s s}$ & 45,2 & 26,7 & 10,0 & 1,7 & $2,4 \%$ & $13,9 \%$ \\
\hline$Z_{44}$ & 42,1 & 30,3 & 10,0 & 1,7 & $1,5 \%$ & $14,3 \%$ \\
\hline$Z_{3 s}$ & 42,8 & 30,8 & 10,3 & 1.7 & $1,3 \%$ & $13,0 \%$ \\
\hline$Z_{\text {sa }}$ & 37,2 & 35,5 & 10,1 & 1,6 & $0,8 \%$ & $15,6 \%$ \\
\hline$Z_{97}$ & 37,6 & 35,8 & 11,8 & 3,5 & $0,5 \%$ & $10,0 \%$ \\
\hline$Z_{\text {в }}$ & 41,6 & 39,8 & 7,2 & 1,8 & $0,7 \%$ & $8,7 \%$ \\
\hline
\end{tabular}




\section{AGLOMERANTES: PORTLAND - CENIZAS DE CENTRAL TERMICA}

\begin{tabular}{|c|c|c|c|c|c|c|}
\hline \multirow{2}{*}{ MARCA } & \multicolumn{6}{|c|}{ RESISTENCIAS $\mathrm{kg} / \mathrm{cm}^{2}$} \\
\hline & \multicolumn{3}{|c|}{ FLEXION } & \multicolumn{3}{|c|}{ COMPRESION } \\
\hline Días & 3 & 7 & 28 & 3 & 7 & 28 \\
\hline$Z_{1}$ & & 20,7 & 39,3 & & 526 & 722,5 \\
\hline$Z_{2}$ & & 25 & 34 & & 563 & 750,8 \\
\hline$Z_{3}$ & & 12,2 & 19,2 & & 191 & 364,5 \\
\hline$Z_{4}$ & & 3,6 & 21,7 & & 889 & 288 \\
\hline to & & & & & & \\
\hline Cem. Ck 144 & & 15,3 & 22,7 & & 333,8 & 482,3 \\
\hline$Z_{s}$ & & 10,1 & 25,4 & & 419,3 & 580 \\
\hline$Z_{k}$ & & 25,6 & 33,1 & & 414 & 529 \\
\hline$Z_{r}$ & & 14,6 & 26,4 & & 228,2 & 360. \\
\hline $\mathrm{z}_{4}$ & & & 7,1 & & 26,1 & 36,6 \\
\hline CEMENTO & 17,9 & 33,8 & 64,0 & 65,5 & 154,2 & 324,5 \\
\hline$Z_{13}$ & 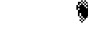 & 50,5 & 63,7 & & 189,7 & 351,5 \\
\hline$Z_{14}$ & & 34,4 & 55,6 & & 176 & 294,6 \\
\hline$Z_{13}$ & & 17,6 & 47,5 & & 50,9 & 203,1 \\
\hline$Z_{16}$ & & 4,5 & 15,5 & & 3,1 & 45,2 \\
\hline$Z_{17}$ & & 8,6 & 24,3 & & 12,6 & 59,8 \\
\hline$Z_{19}$ & & 4,6 & 21 & & 6,2 & 45,3 \\
\hline$Z_{19}$ & & $3, A$ & 11,9 & & 1,5 & 14,2 \\
\hline$Z_{20}$ & & 3 & 12 & & 1,5 & 13,1 \\
\hline
\end{tabular}

MARCA

Dias

Za1

$Z_{22}$

$Z_{\text {I: }}$

$Z_{94}$

$Z_{25}$

$Z_{26}$

$Z_{99}$

$Z_{49}$

$Z_{\text {av }}$

$Z_{\text {B9 }}$

$Z_{34}$

$Z_{85}$

$Z_{\text {ato }}$

$Z_{\text {ar }}$ 
Como puede apreciarse en el cuadro n. 11 , las resistencias de las mezclas compuestas con cenizas $n .{ }^{\circ} 145\left(Z_{1}\right.$ a $\left.Z_{4}\right)$ y $n .^{\circ} 148\left(Z_{5}\right.$ a $\left.Z_{8}\right)$ se ensayaron en proberas preparadas según el Pliego español de 1930, mientras que para todas las demás se aplicaron las normas RILEM. Al usar estas últimas $y$, principalmente, en las series $Z_{17}$ a $Z_{21}$ proyectadas para conocer la in. fluencia de la cantidad de yeso, fué necesario abandonar la proporción de agua, pues con los $500 \mathrm{ml}$ de RILEM la fluidez del mortero era tal que ni a las 72 horas se habría iniciado el endurecimiento minimo necesario para desenmoldar los prismas.

El cemento portland utilizado como punto de referencia y componente de las mezclas $Z_{1}$ a $Z_{24}$ fué un portland preparado en el laboratorio mediante molturación y mezcla de un clínker comercial. En las demás mezclas, el cemento empleado ha sido un supercemento nacional.

Para juzgar en qué medida las cenizas volantes y las de parrillas contribuyen al desarrollo de resistencias mecánicas, se pueden comparar los resultados obtenidos a compresión con la ceniza 145 (mezclas $Z_{1}$ a $Z_{4}$ ) con los alcanzados por la 153 (mezclas $Z_{25}$ a $Z_{31}$ ).

La comparación de las resistencias del cemento tipo apreciadas con el mortero especial, con las alcanzadas por el mismo aglomerante utilizando el mortero RILEM, nos ha permitido reducir a esta última escala los valores de las mezclas $Z_{1}$ a $Z_{4}$, con lo cual es factible la comparación de los valores de estas mezclas con las del grupo $Z_{25}$ a $Z_{31}$.

Los resultados así corregidos, son:

\% cenizas cenizas de parrillas cenizas volantes

\begin{tabular}{lcccc} 
& 7 dias & 28 dias & 7 dias & 28 dias \\
$10 \%$ & 184 & 253 & 131 & 291 \\
$20 \%$ & 199 & 265,5 & 114,5 & 242 \\
$40 \%$ & 67,6 & 129,0 & 48,4 & 120 \\
$80 \%$ & 31,5 & 102 & 3,1 & 26,2 \\
& & 7 dias & 28 días \\
Cemento portland & 154 & \multicolumn{2}{c}{324}
\end{tabular}

El aglomerante obtenido con estas cenizas de parrilla alcanza mejores resistencias, especialmente en mezclas pobres de portland, que el de cenizas volantes, si bien a largo plazo tienden a igualarse.
La influencia que puede tener la cantidad de yeso adicionada se puede apreciar en los ensayos de las mezclas $Z_{17}$ a $Z_{24}$. La serie $Z_{17}-Z_{18}-Z_{19}-Z_{20}$ contienen cenizas volantes en gran proporción $(80 \%$ ) y las dos primeras el yeso, sin refinar, en las proporciones del 2 y $3 \%$, respectivamente, mientras que las dos segundas difieren de ellas en que la mezcla de los tres componentes se refinó. Esto se refleja en los valores de las fracciones separadas en el flourómetro.

Las mezclas $Z_{21}-Z_{29}-Z_{23}-Z_{24}$ son similares a las anteriores, de las que difieren en el menor porcentaje de cenizas; en este caso el $20 \%$.

El cuodro n. 13 reúne todos los resultados. De su examen parece deducirse que las mezclas más ricas en cenizas no ganan resistencias al incrementar el yeso $y$, al contrario, les ocurre con mezclas en que prepondera el portland. Es indiscutible la beneficiosa influencia de la finura. Quizás exista, para cada par de componentes (cenizas-portland), una cantidad óptima de yeso; también habría que experimentar el efecto de los hidratos menos ricos en agua, así como de las anhidritas.

\section{Identificación de las cenizas en los aglomerantes}

El fin, de orden más bien fiscal que científico, de estos ensayos impone ung madurez experimental muy acentuada. Teniendo en cuenta el restringido carácter represenfativo de las muestras que hemos podido utilizar, el estudio se ha llevado a cabo como misión exploratoria, más bien para descartar métodos que para sentar conclu. siones.

Hasta el momenfo hemos utilizado como parámetro la densidad absoluta del material y la cuantía del residuo insoluble. Quedan, en espera de aplicación, el ataque selectivo de los componentes mediante ácidos - bases orgánicos, por ejemplo el ácido picrico, utilizado en la resolución de mezclas portland-puzolana, al parecer con éxito por Fratini en Italia, o las disoluciones de dimetilamina, aplieadas en Alemania por Keil y Gille a las escorias siderúrgicas, y la separación por medio de líquidos que posean una densidad intermedia a la de los componentes de la mezcla. 
De momento estamos ensayando como criterio la variación del resíduo insoluble del aglomerante cuando se le somete, durante un lapso de tiempo, a temperatura de $1.000 \mathrm{C}$ y $1.100 \mathrm{C}$.

En el cuadro n. 14 se tabulan los resultados de las medidas de la densidad. Se utilizó el método del picnómetro y, como líquido picnométrico, el alcohol bencílico, primero, $y$, más tarde, el etílico, pues se pudo apreciar cierta solubilidad de algunas cenizas en el primero, que se utilizaba para beneficiarse del elevado poder de mojadura que posee.

Como se puede apreciar no es la densidad un buen criterio para enjuiciar el problema, especialmente en orden cuanfitafivo, ya que estos maferiales son de una hetereogeneidad tal que, aun dentro de pequeñas porciones, se acusa lo suficiente para producir series de valores tan erráticos que el méłodo pierde eficacia. Si puede aceptarse, en principio, que una densidad baja en un aglomerante normalizado debe poner en guardia acerca de su posible contaminación o gdulteración.

La otra serie de ensayos se realizó aplicando la cuantía del residuo insoluble. Se utilizaron no sólo la técnica del Pliego español vigente (1930), sino también su modificación aplicable a las puzolanas. Es notable la discordancia entre los resultados obtenidos según que se aplique uno $v$ otro método. Cuadro 15.

Desde luego lá variación de la cuantía del residuo se acusa, en forma destacadísj$\mathrm{ma}$ en todas las mezclas y desde la de menor contenido en cenizas $(10 \%)$.

En definitiva, parece este medio uno de los mejores, especialmente si se aplica el método prescrito para los cementos.

\section{Aglomerantes con cenizas volantes}

\section{DENSIDADES}

\begin{tabular}{|c|c|c|c|c|c|c|c|c|c|}
\hline $\begin{array}{c}\text { Mezclas y } \\
\text { componentes }\end{array}$ & $\begin{array}{l}\text { Valor } \\
\text { medio }\end{array}$ & $\begin{array}{l}\text { Volor } \\
\text { caicus } \\
\text { İado }\end{array}$ & & & $\begin{array}{c}\text { Mezzlas y } \\
\text { componentes }\end{array}$ & $\begin{array}{l}\text { Valor } \\
\text { mestio }\end{array}$ & $\begin{array}{l}\text { Volor } \\
\text { colcu- } \\
\text { laddo }\end{array}$ & \multicolumn{2}{|c|}{ Ĺquido } \\
\hline Cemento 144 & 3,06 & & \multicolumn{2}{|c|}{ Alcohol bencííico } & Cemento 142 & 3,08 & & \multicolumn{2}{|c|}{ Alcohol bencilico } \\
\hline$Z_{1}(10 \%)$ & 4,25 & 3,05 & $»$ & $*$ & $Z_{25}(10 \%)$ & 2,67 & 2,97 & 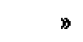 & 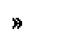 \\
\hline$Z_{8}(20 \%)$ & 3,97 & 3,03 & $»$ & " & $Z_{26}(20 \%)$ & 2,89 & 2,87 & s & * \\
\hline$Z_{3}(40 \%)$ & 3,02 & 2,95 & $»$ & $y$ & $Z_{87}(30 \%)$ & 2,83 & 2,77 & $p$ & $"$ \\
\hline$Z_{4}(80 \%)$ & 2,94 & 2,89 & ${ }^{\prime \prime}$ & * & $Z_{98}(50 \%)$ & 2,75 & 2,61 & 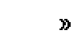 & * \\
\hline Ceniza 145 & 2,87 & & * & $*$ & $Z_{89}(70 \%)$ & 2,54 & 2,46 & 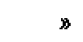 & 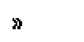 \\
\hline Cemento 142 & 3,08 & & $\Rightarrow$ & " & $Z_{80}(80 \%)$ & 2,47 & 2,39 & $\infty$ & * \\
\hline$Z_{3}(10 \%)$ & 2,88 & 2,84 & $\Rightarrow$ & $*$ & $Z_{\beta 1}(90 \%)$ & 2,46 & 2,33 & \multicolumn{2}{|c|}{ Alcohol etílico } \\
\hline$Z_{e}(20 \%)$ & 2,48 & 2,63 & \% & » & Ceniza 153 & 2,27 & & x & * \\
\hline$Z_{7}(40 \%)$ & 2,56 & 2,04 & $*$ & * & Cemento 142 & 3,08 & & * & $\$$ \\
\hline$Z_{8}(80 \%)$ & 2,23 & 1,83 & $w$ & » & $Z_{a g}(10 \%)$ & 2,84 & 2,93 & * & $*$ \\
\hline Ceniza 148 & 1,67 & & 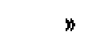 & 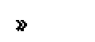 & $Z_{\text {明 }}(20 \%)$ & 2,82 & 2,81 & ע & 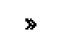 \\
\hline Cemento 142 & 3,08 & & $»$ & * & $Z_{s 4}(30 \%)$ & 2,61 & 2,69 & x & $»$ \\
\hline$Z_{18}(10 \%)$ & 2,77 & 3,02 & $\gg$ & » & $Z_{A 5}(50 \%)$ & 2,37 & 2,48 & $»$ & » \\
\hline$Z_{14}(20 \%)$ & 2,66 & 2,97 & * & * & $Z_{36}(70 \%)$ & 2,28 & 2,30 & * & w \\
\hline$Z_{15}(40 \%)$ & 2,49 & 2,77 & 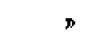 & * & $Z_{a 7}(80 \%)$ & 2,25 & 2,22 & x & * \\
\hline$Z_{10}(80 \%)$ & 2,61 & 2,68 & $\otimes$ & x & $\mathrm{Z}_{80}(90 \%)$ & 244 & 2,15 & n & $\infty$ \\
\hline Cenizo 150 & 2,60 & & $y$ & $n$ & Ceniza 154 & 2,08 & & $\Rightarrow$ & $n$ \\
\hline
\end{tabular}


De momento estamos ensayando como criterio la variación del resíduo insoluble del aglomerante cuando se le somete, durante un lapso de tiempo, a temperatura de $1.000 \mathrm{C}$ y $1.100 \mathrm{C}$.

En el cuadro n. 14 se tabulan los resultados de las medidas de la densidad. Se utilizó el método del picnómetro y, como líquido picnométrico, el alcohol bencílico, primero, $y$, más tarde, el etílico, pues se pudo apreciar cierta solubilidad de algunas cenizas en el primero, que se utilizaba para beneficiarse del elevado poder de mojadura que posee.

Como se puede apreciar no es la densidad un buen criterio para enjuiciar el problema, especialmente en orden cuanfitafivo, ya que estos maferiales son de una hetereogeneidad tal que, aun dentro de pequeñas porciones, se acusa lo suficiente para producir series de valores tan erráticos que el méłodo pierde eficacia. Si puede aceptarse, en principio, que una densidad baja en un aglomerante normalizado debe poner en guardia acerca de su posible contaminación o gdulteración.

La otra serie de ensayos se realizó aplicando la cuantía del residuo insoluble. Se utilizaron no sólo la técnica del Pliego español vigente (1930), sino también su modificación aplicable a las puzolanas. Es notable la discordancia entre los resultados obtenidos según que se aplique uno $v$ otro método. Cuadro 15.

Desde luego lá variación de la cuantía del residuo se acusa, en forma destacadísj$\mathrm{ma}$ en todas las mezclas y desde la de menor contenido en cenizas $(10 \%)$.

En definitiva, parece este medio uno de los mejores, especialmente si se aplica el método prescrito para los cementos.

\section{Aglomerantes con cenizas volantes}

\section{DENSIDADES}

\begin{tabular}{|c|c|c|c|c|c|c|c|c|c|}
\hline $\begin{array}{c}\text { Mezclas y } \\
\text { componentes }\end{array}$ & $\begin{array}{l}\text { Valor } \\
\text { medio }\end{array}$ & $\begin{array}{l}\text { Volor } \\
\text { caicus } \\
\text { İado }\end{array}$ & & & $\begin{array}{c}\text { Mezzlas y } \\
\text { componentes }\end{array}$ & $\begin{array}{l}\text { Valor } \\
\text { mestio }\end{array}$ & $\begin{array}{l}\text { Volor } \\
\text { colcu- } \\
\text { laddo }\end{array}$ & \multicolumn{2}{|c|}{ Ĺquido } \\
\hline Cemento 144 & 3,06 & & \multicolumn{2}{|c|}{ Alcohol bencííico } & Cemento 142 & 3,08 & & \multicolumn{2}{|c|}{ Alcohol bencilico } \\
\hline$Z_{1}(10 \%)$ & 4,25 & 3,05 & $»$ & $*$ & $Z_{25}(10 \%)$ & 2,67 & 2,97 & 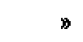 & 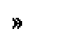 \\
\hline$Z_{8}(20 \%)$ & 3,97 & 3,03 & $»$ & " & $Z_{26}(20 \%)$ & 2,89 & 2,87 & s & * \\
\hline$Z_{3}(40 \%)$ & 3,02 & 2,95 & $»$ & $y$ & $Z_{87}(30 \%)$ & 2,83 & 2,77 & $p$ & $"$ \\
\hline$Z_{4}(80 \%)$ & 2,94 & 2,89 & ${ }^{\prime \prime}$ & * & $Z_{98}(50 \%)$ & 2,75 & 2,61 & 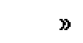 & * \\
\hline Ceniza 145 & 2,87 & & * & $*$ & $Z_{89}(70 \%)$ & 2,54 & 2,46 & 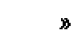 & 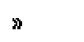 \\
\hline Cemento 142 & 3,08 & & $\Rightarrow$ & " & $Z_{80}(80 \%)$ & 2,47 & 2,39 & $\infty$ & * \\
\hline$Z_{3}(10 \%)$ & 2,88 & 2,84 & $\Rightarrow$ & $*$ & $Z_{\beta 1}(90 \%)$ & 2,46 & 2,33 & \multicolumn{2}{|c|}{ Alcohol etílico } \\
\hline$Z_{e}(20 \%)$ & 2,48 & 2,63 & \% & » & Ceniza 153 & 2,27 & & x & * \\
\hline$Z_{7}(40 \%)$ & 2,56 & 2,04 & $*$ & * & Cemento 142 & 3,08 & & * & $\$$ \\
\hline$Z_{8}(80 \%)$ & 2,23 & 1,83 & $w$ & » & $Z_{a g}(10 \%)$ & 2,84 & 2,93 & * & $*$ \\
\hline Ceniza 148 & 1,67 & & 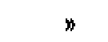 & 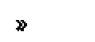 & $Z_{\text {明 }}(20 \%)$ & 2,82 & 2,81 & ע & 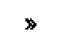 \\
\hline Cemento 142 & 3,08 & & $»$ & * & $Z_{s 4}(30 \%)$ & 2,61 & 2,69 & x & $»$ \\
\hline$Z_{18}(10 \%)$ & 2,77 & 3,02 & $\gg$ & » & $Z_{A 5}(50 \%)$ & 2,37 & 2,48 & $»$ & » \\
\hline$Z_{14}(20 \%)$ & 2,66 & 2,97 & * & * & $Z_{36}(70 \%)$ & 2,28 & 2,30 & * & w \\
\hline$Z_{15}(40 \%)$ & 2,49 & 2,77 & 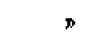 & * & $Z_{a 7}(80 \%)$ & 2,25 & 2,22 & x & * \\
\hline$Z_{10}(80 \%)$ & 2,61 & 2,68 & $\otimes$ & x & $\mathrm{Z}_{80}(90 \%)$ & 244 & 2,15 & n & $\infty$ \\
\hline Cenizo 150 & 2,60 & & $y$ & $n$ & Ceniza 154 & 2,08 & & $\Rightarrow$ & $n$ \\
\hline
\end{tabular}




\section{Aglomerantes con cenizas volantes}

\section{RESIDUO INSOLUBLE}

\begin{tabular}{|c|c|c|c|c|c|c|c|}
\hline \multicolumn{2}{|c|}{ MATERIAL } & $\begin{array}{l}\text { Caicu. } \\
\text { lado }\end{array}$ & Media & $\begin{array}{c}\text { Pliego español } \\
\%_{0}\end{array}$ & $\begin{array}{l}\text { Calcu- } \\
\text { lado }\end{array}$ & Media & $\begin{array}{c}\text { Método para } \\
\text { puzolanas } \\
\oint_{q}\end{array}$ \\
\hline \multicolumn{2}{|c|}{$\begin{array}{l}\text { Ceniza } 145 \\
\text { Cemento } 144 \\
Z_{1} 10 \% \text { ceniza }\end{array}$} & $\begin{array}{r}6,95 \\
13,48 \\
26,53 \\
52,64\end{array}$ & $\begin{array}{r}65,75 \\
0,42\end{array}$ & $\begin{array}{r}66,31-65,20 \\
0,39-0,44 \\
7,18-7,11 \\
11,19-10,41 \\
25,03-25,76 \\
48,93-47,46\end{array}$ & & & $\begin{array}{r}3,18 \cdot 3,31 \\
10,25-7,58 \\
14,80-15,40 \\
28,85-28,76\end{array}$ \\
\hline \multicolumn{2}{|c|}{$\begin{array}{l}\text { Ceniza } 148 \\
\text { Cemento } 142 \\
Z_{\mathrm{L}} \text { T0\% ceniza }\end{array}$} & $\begin{array}{l}10,87 \\
20,00 \\
38,41 \\
75,12\end{array}$ & $\begin{array}{r}93,48 \\
1,69\end{array}$ & $\begin{array}{r}93,28-93,68 \\
1,65-1,73 \\
11,04-11,11 \\
20,25 \cdot 20,40 \\
39,60-37,58 \\
75,52-75,23\end{array}$ & $\begin{array}{r}5,84 \\
9,89 \\
17,98 \\
34,15\end{array}$ & $\begin{array}{r}42,24 \\
1,80\end{array}$ & $\begin{array}{r}42,34-42,14 \\
1,88-1,76 \\
10,33-15,73 \\
18,07-24,97 \\
33,91-33,68 \\
68,42-67,71\end{array}$ \\
\hline \multicolumn{2}{|c|}{$\begin{array}{l}\text { Ceniza } 150 \\
\text { Cemento } 142 \\
Z_{18} 10 \% \text { ceniza }\end{array}$} & $\begin{array}{r}8,80 \\
15,90 \\
30,12 \\
58,55\end{array}$ & $\begin{array}{r}72,77 \\
1,69\end{array}$ & $\begin{array}{r}72,54-73,00 \\
1,65-1,73 \\
9,51-9,85 \\
19,51-19,79 \\
38,82-38,37 \\
61,99-61,83\end{array}$ & $\begin{array}{r}6,10 \\
10,40 \\
18,97 \\
36,12\end{array}$ & $\begin{array}{r}44,70 \\
1,80\end{array}$ & $\begin{array}{r}45,02-44,38 \\
1,88-\quad 1,76 \\
6,15-5,70 \\
14,06-13,37 \\
24,06-25,01 \\
42,82-43,12\end{array}$ \\
\hline $\begin{array}{l}\text { Ceniza } 15 \\
\text { Cemento } \\
Z_{98} 10 \% \\
Z_{s 0} 20 \% \\
Z_{87} 30 \% \\
Z_{38} 50 \% \\
Z_{28} 70 \% \\
Z_{30} 80 \% \\
Z_{91} 90 \%\end{array}$ & 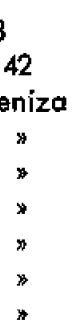 & $\begin{array}{r}8,01 \\
16,33 \\
23,65 \\
38,30 \\
52,94 \\
60,24 \\
67,58\end{array}$ & $\begin{array}{r}74,90 \\
1,69\end{array}$ & $\begin{array}{r}77,81-72,48 \\
1,65-1,73 \\
9,89-9,88 \\
17,53-18,00 \\
24,40-24,52 \\
41,65-41,44 \\
55,17-56,23 \\
65,62-66,28 \\
73,05-73,30\end{array}$ & $\begin{array}{r}7,14 \\
12,47 \\
17,79 \\
28,44 \\
39,08 \\
44,40 \\
49,73\end{array}$ & $\begin{array}{r}55,05 \\
1,80\end{array}$ & $\begin{array}{r}54,94-55,16 \\
1,88-1,76 \\
6,49-6,33 \\
12,84-12,77 \\
16,73-17,32 \\
28,08-28,09 \\
39,56-39,83 \\
43,73-44,03 \\
48,86-49,16\end{array}$ \\
\hline $\begin{array}{l}\text { Ceniza } 15 \\
\text { Cemento } \\
Z_{38} 10 \% \\
Z_{s 3} 20 \% \\
Z_{: 44} 30 \% \\
Z_{95} 50 \% \\
Z_{a b} 70 \% \\
Z_{37} 80 \% \\
Z_{9 B} 90 \%\end{array}$ & $\begin{array}{l}42 \\
\text { eniza } \\
\vdots \\
" \\
" \\
" \\
"\end{array}$ & $\begin{array}{l}11,05 \\
20,40 \\
29,76 \\
48,48 \\
67,19 \\
76,53 \\
85,90\end{array}$ & $\begin{array}{r}95,26 \\
1,69\end{array}$ & $\begin{array}{r}95,35-95,18 \\
1,65-1,73 \\
11,07 \cdot 11,20 \\
30,05 \cdot 20,14 \\
20,31-29,70 \\
48,58-48,31 \\
66,52-65,97 \\
76,30=76,15 \\
85,60-85,48\end{array}$ & $\begin{array}{l}10,24 \\
18,66 \\
27,09 \\
43,94 \\
60,79 \\
69,21 \\
77,63\end{array}$ & $\begin{array}{r}86,06 \\
1,80\end{array}$ & $\begin{array}{r}86,26-85,83 \\
1,88-1,76 \\
9,46-9,46 \\
17,89-18,08 \\
26,96-27,28 \\
43,17-43,10 \\
59,90-59,61 \\
69,51-76,29 \\
77,21-77,21\end{array}$ \\
\hline
\end{tabular}

